\title{
SOCIOCULTURAL URBAN SPACE IN E-SOCIETY
}

\author{
Olga Kononova ${ }^{1}$, Dmitry Prokudin ${ }^{1,2}$ and Vitalina Karachay ${ }^{1}$ \\ ${ }^{1}$ St. Petersburg National Research University of Information Technologies, Mechanics and Optics (ITMO University), \\ 197101, St. Petersburg, Russia \\ ${ }^{2}$ St. Petersburg State University, 199034, St. Petersburg, Russia
}

\begin{abstract}
The study focuses on the sociocultural aspects of urban development. Paper presents the complete deterministic concept of service oriented Sociocultural Information Urban Space (SIUS), considered as a logical development of the intercultural-communicational, technical-resource approaches and social machine concept in order to studying and understanding the features, possibilities, and base information flows of the Smart City sociocultural face. The SIUS idea helps to recognize or improve the data driving city concept because of smart technology use, so that greater range of digital services related to the sociocultural city facets can be provided to different stakeholders. The study includes exploring the interaction of pervasive processes of the urban space, specification of the SIUS architecture and concept. Based on principles and practices of the pervasive approach, the main mechanisms of citizens' involvement into the active creative development of the SIUS are identified. Moreover, the study discusses two application scenarios which demonstrate how pervasive processes of sustainable development and pervasive self-regulation mechanisms of SIUS can be used in order to consider the factual needs of citizens and decision-making.
\end{abstract}

\section{KEYWORDS}

Smart City, Social Machine, Smart Technology, Sociocultural Information Urban Space, e-Society

\section{INTRODUCTION}

Global urbanization has significantly increased over the past few centuries. The growth of the world's cities is ingrained in a culture of short-term economic benefit and often raging consumption and production practices that compromise the sustainability of the environment (World Cities Report, 2016). Modern urbanization process and urbanism have been basically conditioned by technological changes and by the organization of the city and society as a media-sphere (Wakabayashi, 2002). In this regard, the issue of description and feature characteristics determination of Sociocultural Information Urban Space (SIUS) and the study of motivation mechanisms identification for citizens' participation in the decision-making processes in urban development domain become relevant. The present research is aimed at identifying the mechanisms of citizens' involvement into Sociocultural Information Urban Space. The following tasks were specified in the paper: identify, study and classify the main SIUS subjects and objects and its interactions; based on the analysis of existing methods and approaches, including the investigation of the Sociocultural Information Urban Space of St. Petersburg, identify the main mechanisms of citizens' involvement into the active creative development of the SIUS. The authors propose a new concept of Sociocultural Information Urban Space, which is the evolutionary development of the existing conceptions. SIUS of the modern city is viewed in this paper as an interactive form of communication between the urban environment subjects. Our interests focus on the supplementation of existing interaction forms and types of actors within the framework of traditional social and cultural institutions, as well as on the development of the intellectual and creative activity of the people, both in real and virtual space. The study can be considered as a source of knowledge and facilitates the better urban design, making it more functioning and more sustainable; optimize the use of limited resources and make better decisions in the Smart City. 


\section{RELATED WORKS}

It should be noted that the progress in ICT solutions enables not only the public and private sector, but also offers the potential for information urban space. In this regard, the essential research issue is increasing the citizen participation via efficient service provision and democracy instruments as key factor of the dynamic modern city promotion. Based on the overview of previous works, the following approaches to the information urban space were distinguished. In particular, the information environment can be viewed as the intercultural communication space, where the ICTs promote mutual recognition among peoples and their cultures (Drotianko and Yahodzinskyi, 2017). Technical (or resource) approach to the information environment defines it via the information, stored and circulating within this environment. Whereas, the sociocultural concepts of the information environment refer to the space of social communications and identify it as an integral part of the culture (Sokolova, 2002). According to the Belon et al. (2015), sociocultural space is a complex, dynamic construct that encompasses the community's social and cultural context that shapes beliefs, values, and practices, that may foster individual efforts to participate in physical activity. In the field of Human Computer Interaction (HCI), the sociocultural information space can be considered, focusing on studying the interactions and the relationships between humans and computers (Sharma and Mehta, 2016). Besides, the information space can be described as the environment where information is handled in order to navigate through the city (Masucci et al., 2014). The ecosystem approach (Ahlers et al., 2019) defines a large-scale smart city IT architecture that spans multiple actors in open and collaborative way, focused on the ICT aspect of the Smart City concept. This approach was designed to be open to additional stakeholders in and around a city, and to enable smart city evolution as an ongoing process. According Falco and Kleinhans (2018), the most important factor for innovative communication in the information space is understanding (at the management level) of the benefits that could be gained through advanced digital participatory platforms (DPPs) and social media in general. However, Barns (2018) argues that urban data platforms should aim to support the role of city governments in cultivating partnerships spanning public and private data custodians, citizens and software developers. This approach can better support more collaborative models of smart city governance ('smart cities 2.0 '). Summarizing the overview of the related works, there are three main directions in the information urban space domain: technical/resource aspect, intercultural one, and social machine aspect (Table 1).

Table 1. Urban Space Approaches

\begin{tabular}{|c|c|c|}
\hline Intercultural Communication Space & Technical-Resource Approach & A Social Machine \\
\hline \multicolumn{3}{|c|}{ Specific aspects: } \\
\hline $\begin{array}{l}\text { predetermination, weak human- } \\
\text { dependent technology }\end{array}$ & $\begin{array}{l}\text { sociotechnical, organizational } \\
\text { sustainability }\end{array}$ & $\begin{array}{l}\text { a social machine design is not a given, } \\
\text { but a dialectic }\end{array}$ \\
\hline \multicolumn{3}{|c|}{ Authors and Opinions } \\
\hline Belon et al., 2015 & Masucci et al., 2014 & Berners-Lee and Fischetti, 1999 \\
\hline $\begin{array}{l}\text { a complex, dynamic construct that } \\
\text { encompasses the community's } \\
\text { social and cultural context }\end{array}$ & $\begin{array}{l}\text { the information is handled in } \\
\text { order to navigate through the city }\end{array}$ & $\begin{array}{l}\text { humans and technology interacting and } \\
\text { producing outputs or action, which } \\
\text { would not be possible without both } \\
\text { parties present }\end{array}$ \\
\hline Drotianko and Yahodzinskyi, 2017 & Ahvenniemi et al., 2017 & Castronova, 2005 \\
\hline $\begin{array}{l}\text { mutual recognition among peoples } \\
\text { and their cultures }\end{array}$ & $\begin{array}{l}\text { a process automation of data } \\
\text { acquisition, storage, organization } \\
\text { and analysis with the technologies }\end{array}$ & $\begin{array}{l}\text { games and gamification: the players } \\
\text { interact both with each other and with } \\
\text { programmed machine features }\end{array}$ \\
\hline Falco and Kleinhans, 2018 & Yaxue Ma et al., 2018 & Shadbolt et al., 2019 \\
\hline $\begin{array}{l}\text { digital participatory platforms as a } \\
\text { specific kind of collaborative social } \\
\text { media }\end{array}$ & $\begin{array}{l}\text { a forming of an urban data service } \\
\text { system, covering the entire } \\
\text { process of data collection, } \\
\text { organization, analysis and } \\
\text { management }\end{array}$ & $\begin{array}{l}\text { there is no simple dividing line between } \\
\text { the human and the technological (a } \\
\text { particular function is performed by a } \\
\text { person or a computer) }\end{array}$ \\
\hline
\end{tabular}

The social machine approaches take into account the social aspect, and, to our mind, look like the most constructive ones (Berners-Lee and Fischetti, 1999). Social machines are co-created by human participants and technological components (Shadbolt et al., 2019). They bring people together, using technology to enable communication and cooperation at scale. Castronova (2005) considers games and gamification as examples 
of social machines, as the players, possibly using avatars or alternative identities, interact both with each other and with programmed machine features in a synthetic environment. The concept of digital urban space (Ma et al., 2018) proposes to use urban big data sensed from urban Cyber-Physical-Social spaces by transformation into smart data to meet the needs of urban management and operation. This approach is a kind of pragmatic and utility, however, does not sufficiently take into account the concept of social machine. It should be noted that none of the concepts gives a complete picture of the complexity and features of the Sociocultural Information Urban Space. Moreover, most of the concepts do not include the methods and information models for citizen's engagement in its formation and mechanisms to motivate the citizens' participation in decision-making in urban development sphere. The given research is filling this gap, presenting complete deterministic concept of service oriented SIUS.

\section{SOCIOCULTURAL INFORMATION URBAN SPACE DESIGN}

In order to clarify the understanding of the structure and composition of the Information Urban Space in sociocultural aspect, three initial concepts, associated with information space, have been reviewed and compared: Social Machine, Intercultural Communication Space, Technical-Resource Approach. It has allowed suggesting a hybrid Sociocultural Information Urban Space (SIUS) approach.

Sociocultural Information Urban Space, in our opinion, is an evolutionary development of concepts, presented above (Kononova et al., 2019). It has unique features - the ability to self-organization and self-development that is the most important for the modern smart city sustainability. There are two scenarios for the investigation and the design such space at once: top-down design (purposeful planning' view which identifies initiatives of city authorities, government structures, and business) and bottom-up design (entropy' view which identifies personal and public initiatives).

The idea to focus on the city sociocultural development gets reflected in the case-study on the instance of the project 'The Smart City Saint Petersburg'. SIUS of the modern city is viewed in this paper as an interactive form of communication between the subjects of the urban space.

Designing of SIUS architecture is necessary to identify sustainable relationships between its objects and subjects that determines the cultural environment of the modern smart city formation and its sustainable development. Building the SIUS architecture will determine the main mechanisms of citizens' involvement into the sociocultural information urban space.

Based on the city construction (Ma et al., 2018), we propose specific approach to the Sociocultural Information Urban Space formation, represented as one of the components of Smart Living (Giffinger et al., 2010). There are following main components of the SIUS in the electronic network environment: Internet sites; service-oriented Internet portals; social network. Besides, the components are divided into several main levels: administrative, organization-oriented level, commercial, socially oriented level.

\section{ST. PETERSBURG CASE}

The sociocultural information urban space of St. Petersburg has been chosen as the base of the empirical study. It was determined by following issues: researchers are the St. Petersburg SIUS subjects and they are involved into the processes of interaction with it; St. Petersburg is the cultural capital of Russia, and therefore, its sociocultural information space is the most developed among all Russian cities. It pervasive, and contains all the diversity of Russian culture, and the development of information infrastructure allow to identify the main components of the information cultural space. It is worth to note, that the modern Smart City focuses not only on certain technology packages, but forms a new society; the city solving sociocultural problems defines a breakthrough into the future. One of the developed directions of activity within the framework of the Smart City is the "Smart Environment". In the concept of "The Smart City St. Petersburg" project the principles affected the challenges of smart urban environment and Saint Petersburg' Smart City Architecture were formulated. According to the Conception (2019), smart urban environment: provides the needs and expectations of all citizens in all situations of life; aggregates open data, services and tools for its use; improves the quality of information interaction of all participants in urban processes; creates wide opportunities for self-realization for all categories of residents. 
The approach involves the development of all elements that determine the cultural and historical code of the city, that emphasizes the pervasive nature of the smart urban environment and the importance of the main features of SIUS, as stated above. In accordance with the proposed approach to the formation of the information cultural space of the city, various network information resources, which represent different levels of the developed architecture, were considered. The interconnected components were defined, and the flow of information was revealed with the help of the expert method. To illustrate the pilot study, the example of "Afisha" commercial project in SIUS structure is given below (Figure 1) (Kononova et al., 2019). The "Afisha" is one of the largest commercial projects for tickets sale for cultural, sports and other events in Russia. The information (tickets) suppliers are theaters, cinemas, concert halls, music clubs, exhibition halls, museums etc. The Afisha has several information projects, which are represented by separate sites on the Internet. Besides, the Afisha is presented in social networks. Information resources, associated with this commercial project, form a single information space, which implements the various functions of the proposed approach to SIUS formation.

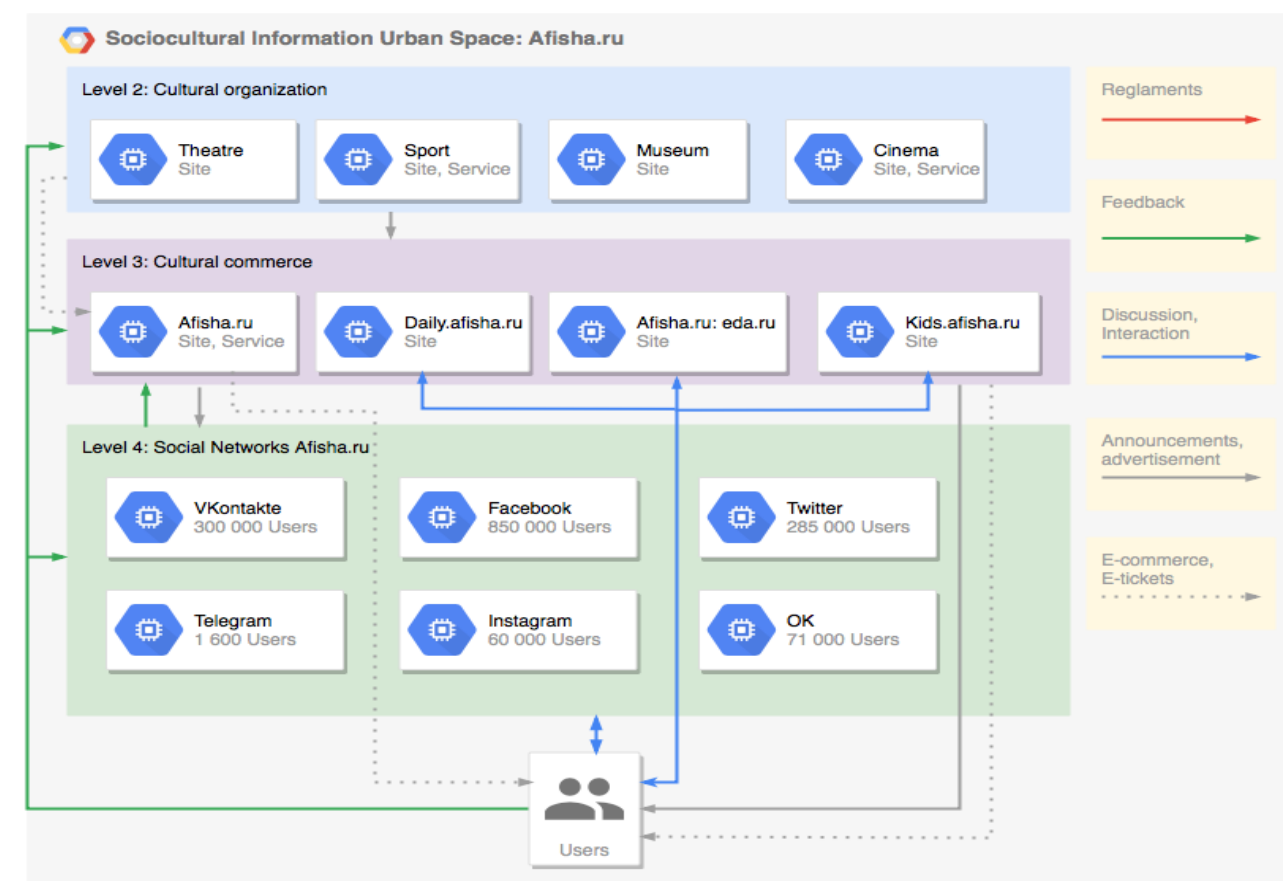

Figure 1. "Afisha” Commercial Project in SIUS Structure

\section{CONCLUSION}

In the result of the study the following items are concluded: the main subjects and objects of Sociocultural Information Urban Space (SIUS) and its interactions are identified; the main processes of SIUS are established; the Sociocultural Information Urban Space architecture has been developed, taking into account the pervasiveness peculiarities of the sociocultural space of the modern city; based on the analysis of Sociocultural Information Urban Space of St. Petersburg, various mechanisms of citizens' engagement into the active creative development of SIUS are revealed; It was found that the sustainable development of the modern information urban space is possible with maximum consideration of information flows: the sustainability is provided by information flows "from above" (formed by public and municipal authorities, cultural institutions and business); development is provided by information flows "from below" (people' initiatives and needs expressed in its activity in the SIUS); creative activity (Social Machines) and initiatives in SIUS should be supported by citizens presence and activity at all levels of architecture. The study can be considered as a source of knowledge and facilitates the better urban design, making it more functioning and more sustainable; optimize the use of limited resources and make better decisions in a Sociocultural Information Urban Space. 


\section{REFERENCES}

Ahlers, D. et al, 2019. A Smart City Ecosystem Enabling Open Innovation. In: Lüke, K.-H., Eichler, G., Erfurth, C., Fahrnberger, G. Innovations for Community Services. 19th International Conference, I4CS 2019, Wolfsburg, Germany, June 24-26, Proceedings, pp. 109-122. DOI: https://link.springer.com/book/10.1007\%2F978-3-03022482-0.

Ahvenniemi, H. et al, 2017. What are the Differences Between Sustainable and Smart Cities? Cities, Vol. 60 (2017), pp. 234-245.

Barns, S., 2018. Smart Cities and Urban Data Platforms: Designing Interfaces for Smart Governance. City, Culture and Society, 12, pp. 5-12.

Belon, A. P. et al, 2015. Community Lenses Revealing the Role of Sociocultural Environment on Physical Activity. In Am J Health Promot. Vol. 30, No. 3, pp. e92-e100. DOI: 10.4278/ajhp.140428-QUAL-169.

Berners-Lee, T. and Fischetti, M., 1999. Weaving the Web: The Original Design and Ultimate Destiny of the World Wide Web by its inventor. Britain: Orion Business. ISBN 978-0-7528-2090-3.

Castronova E., 2005. Synthetic Worlds: the Business and Culture of Online Games. University of Chicago Press, Chicago.

Conception of St. Petersburg Development with the Help of 'Smart City' Technologies (Kontseptsia Razvitiya $\begin{array}{lllll}\text { Sankt-Peterburga } & \text { S } & \text { Pomoshchyu } & \text { Tekhnologiy }\end{array}$ https://docs.wixstatic.com/ugd/548461_be60daeea6ca4768944e3af8344ba8b5.pdf.

Drotianko, L. and Yahodzinskyi, S., 2017. Information Environment as the Intercultural Communication Space. MATEC Web Conf., Vol. 106. 01006. DOI: 10.1051/matecconf/201710601006.

Falco, E. and Kleinhans R., 2018. Beyond Technology: Identifying Local Government Challenges for Using Digital Platforms for Citizen Engagement. International Journal of Information Management, Vol. 40, pp. 17-20.

Giffinger, R. and Gudrun, H., 2010. Smart cities ranking: an effective instrument for the positioning of the cities? Architecture City \& Environment, Vol. 6, No. 12, pp. 7-26.

Kartman, G, Sandnes, A., Smit, G., 2011. Creating Municipal ICT Architectures. A Reference Guide from Smart Cities. https://joinup.ec.europa.eu/document/eu-creating-municipal-ict-architectures-reference-guide-smart-cities.

Kononova O., Karachay V., Pilysova D., Prokudin D., 2019. Sociocultural Information Urban Space Construction. In Proceedings of the international conferences ICT, Society and Human Beings 2019, Connected Smart Cities 2019 and Web Based Communities and Social Media 2019, Porto, Portugal, July 17 - 19, 2019. Edited by Piet Kommers and Guo Chao Peng, IADIS Press, 2019. 456 p. Pp. 105-112. http://www.iadisportal.org/digital-library/socioculturalinformation-urban-space-construction.

Ma, Y. et al., 2018. City profile: using smart data to create digital urban spaces. ISPRS Ann. Photogramm. Remote Sens. Spatial Inf. Sci., Vol. IV-4/W7, pp. 75-82. DOI:10.5194/isprs-annals-IV-4-W7-75-2018.

Masucci, P. A. et al, 2014. Exploring the Evolution of London's Street Network in the Information Space: a Dual Approach. In Phys. Rev. E, Vol. 89, No. 1, 012805. DOI: 10.1103/PhysRevE.89.012805.

Narmeen, Z. B. and Jawwad, A. S., 2015. Smart City Architecture: Vision and Challenges. In International Journal of Advanced Computer Science and Applications, Vol. 6, No. 11, (2015), pp. 246-255. DOI: 10.14569/IJACSA.2015.061132.

Sharma, S. and Mehta, V., 2016. Socio-Cultural Context of Human Computer Interaction (HCI) in Online Shopping Environment. In Apeejay-Journal of Management Sciences and Technology, Vol. 4, No.1, pp. 26-36. https://apeejay.edu/aitsm/journal/docs/issue-oct-2016/ajmst040103.pdf.

Shadbolt, N., O’Hara, K., De Roure, D., Hall, W., 2019. The Theory and Practice of Social Machines. Springer Nature Switzerland AG, Switzerland. DOI: 10.1007/978-3-030-10889-2.

Sokolova, I. V., 2002. Sotsialnaya Informatika (Social Informatics). MGSU Publisher, Moscow, pp. 256.

Wakabayashi, M., 2002. Urban Space and Cyberspace: Urban Environment in the Age of Media and Information Technology. International Journal of Japanese Sociology. Vol. 11, No. 1, pp. 6-18. DOI: 10.1111/1475-6781.00014.

World Cities Report 2016. Urbanization and Development: Emerging Futures. United Nations Human Settlements Programme (UN-Habitat). http://wcr.unhabitat.org/wp-content/uploads/sites/16/2016/05/WCR-\%20Full-Report2016.pdf. 